\title{
EL ESPACIO KANTIANO: INTERPRETACIONES RECIENTES *
}

ISABEL CABRERA

INSTITUTO DE INVESTIGACIONES FILOSÓFICAS

UNIVERSIDAD NACIONAL AUTÓNOMA DE MÉ́XICO

No es casual que la "Estética trascendental", un texto de escasas 40 páginas en un libro de más de 880, haya sido tan importante para Kant, y tan comentado por los intérpretes de entonces y de ahora. La Estética, con su usual acento en el espacio, ${ }^{1}$ establece un ámbito sensible a partir del cual trazar un criterio de legitimidad para el uso de los conceptos puros, e introduce de manera decisiva una de las tesis más conflictivas de la filosofía kantiana: la distinción entre fenómeno y cosa en sí.

En lo siguiente quisiera discutir el argumento que respalda esta problemática distinción entre fenómeno y cosa en sí. La idea de una realidad dicotomizada en realidad en sí y realidad fenoménica, la idea de una presencia fantasmal que parece paralela a nuestra realidad empírica resulta más conflictiva que productiva. ¿Pero de dónde surge esta tesis? Si rastream. s en la Estética encontramos una introducción llena de definiciones, y lue so lo que Kant llama exposiciones "metafísica" y "trascendental": la prime a se ocupa de dar los argumentos para demostrar que el espacio y el tit-mpo son a priori, y que son intuiciones y no conceptos; la segunda, en cambio, intenta mostrar que dicha concepción del espacio y el tiempo nos permite explicar el carácter sintético a priori de las proposiciones de la geometría y de la matemática. Después de esto, Kant dedica básicamente el resto del texto a desarrollar su idea de que el espacio y el tiempo son "formas de la sensibilidad", y es dentro de esta última discusión donde surge la tesis de una realidad fenoménica y una realidad en sí. De hecho, el argumento que sustenta dicha dicotomía puede señalarse claramente: es aquel que, al final de la exposición trascendental, concluye la subjetividad del espacio:

* Agradezco a Salma Saab, Pedro Stepanenko y José de Teresa los valiosos comentarios a una versión anterior de este trabajo, son puntos importantes los que he modificado gracias a sus observaciones.

1 Se ha señalado, con razón, que en la Estética, Kant se ocupa fundamentalmente del espacio, y con respecto al tiempo sólo copia los argumentos y recoge las conclusiones; paralelo a esto está el hecho de que la geometria sea aquí mucho más importante que la matemática. La discusión del tiempo en general será vital para la Analítica posterior, y la discusión sobre la matemática será más extensa al final de la Crítica (cfr. A 707-739, B 735-767). 
Mas, ¿cómo puede estar en el espíritu una intuición externa que precede a los objetos mismos y en la cual el concepto de estos últimos puede ser determinado a priori? Manifiestamente no puede estar de otro modo que teniendo su asiento en el sujeto, como propiedad formal de éste de ser afectado por objetos y así de recibir representación inmediata de estos últimos, es decir, intuición. Esto es, sólo como forma del sentido externo en general. (G.M. B 41) ${ }^{2}$

A partir de entonces, Kant dirá que el espacio es sólo "la forma del sentido externo", válida para todo aquello que nos es dado (es decir, empíricamente real), e irreal para las cosas tomadas independientemente de su relación con nuestra sensibilidad (es decir, trascendentalmente ideal). La distinción entre realidad fenoménica y realidad en sí se desprende, al parecer, de la tesis de la subjetividad del espacio, lo cual a su vez pretende ser la conclusión "manifiesta" de la exposición metafísica que precede.

Pero la mayoría de los intérpretes que conozco cuestionan este optimista "manifiestamente" (Offenbar). Lo que es manifiesto, piensan, es que el argumento requiere de algo más que optimismo. Pero antes de analizar este argumento, podemos preguntarnos si aceptándolo efectivamente nos vemos comprometidos con la idea de una realidad dicótoma. ¿Podría suceder que las formas fueran subjetivas y, sin embargo, ello no implicara cambios en la ontología básica de la filosofía kantiana? ¿Podría suceder que el espacio fuera una forma de toda representación de objetos externos, pero también fuera una propiedad de los objetos externos? Esgrimir esta alternativa constituye una vieja pero reiterada objeción a la concepción kantiana, la cual es formulada claramente, entre otros, por Körner, quien parte de la usual analogía de que las formas son subjetivas a manera de unos lentes que inevitablemente traemos puestos y que tiñen todo lo que vemos de cierto color, a partir de aquí Körner señala:

Siempre sería lógicamente posible que lo que percibimos bajo la forma del espacio y del tiempo se halle ordenado independientemente de nuestra percepción. Es muy posible que lo que una persona ve a través de sus inamovibles gafas, como, por ejemplo, rosa, sea de hecho rosa también, y que así pudiera verse incluso si per impossibile las gafas se quitaran. ${ }^{3}$

2 Las cursivas son de Kant; las negritas, mías. En general retomo la traducción de Pedro Ribas (Alfaguara, Madrid). En las pocas ocasiones en que prefiero la de García Morente (Porrúa, México, col. Sepan-Cuántos) lo indico — con las iniciales G.M.- al final de la cita correspondiente.

3 Körner, Kant, trad. de Ignacio Zapata, Alianza, Madrid, 1977 (Alianza Universidad), pp. 35-36. Esta objeción, que sugiere una tercera opción desatendida por Kant, tiene una historia muy larga; entre sus últimas formulaciones están, a principios de siglo, la de Kemp Smith quien dice: "Kant reconoce sólo dos objetivos: o bien el espacio es conocido como objetivo a posteriori, o bien es una representación a priori, originalmente subjetiva. Pero existe una tercera opción: que a pesar de que nuestra intuición del espacio sea originalmente subjetiva, el espacio mismo sea una propiedad inherente de las cosas en si" (A Comentary to Kant's Critique 
Lo que sugiere esta objeción, conocida como "la tercera alternativa desatendida por Kant", es que aun aceptando que el espacio y el tiempo sean formas subjetivas podría suceder que no sólo fueran formas subjetivas, sino además propiedades de la realidad. No obstante, lo que le interesa a Kant es la legitimidad del conocimiento independientemente de si se da o no esta coincidencia entre realidad en sí y realidad fenoménica, coincidencia que, por lo demás, nunca podríamos justificar. Kant pone el acento en la realidad que conocemos como espacial, independientemente de si ésta coincide o no con aquello a lo que pretende referirse nuestro concepto de una "realidad última", de una realidad tomada como es en sí, con independencia de su ser un objeto de conocimiento.

Sin embargo, Kant cae en la tentación, repetidas veces en la Estética, de hablar de la incognoscible realidad en sí, y de usarla como contraste para iluminar su postura sobre el espacio y el tiempo respecto a las interpretaciones anteriores. El término 'realidad en sí parece reservarse para señalar la realidad a la que pretenden referirse aquellos que consideran el espacio como algo más que una "forma subjetiva", quienes consideran el espacio y el tiempo como algo real o como relaciones entre -0 propiedades de - cosas reales. Es el uso reiterado de Kant de esta distinción lo que vuelve la objeción de la "alternativa desatendida" pertinente. Además, el hecho de que la distinción comience tras el argumento de la subjetividad del espacio parece sugerir que la diferencia está dada en virtud del criterio de espacialidad: de los fenómenos externos tenemos intuiciones espaciales, mientras que de las cosas en sí no tenemos representaciones intuitivas, lo cual nos hace sospechar que podrían no ser espacio-temporales. En este contexto, si la realidad fenoménica (la realidad que podemos intuir) y la realidad en sí (la realidad independientemente de si podemos o no intuirla) fueran ambas espacio-temporales, quizá ya no tendría sentido alguno la distinción.

No es claro, sin embargo, que de esta manera la distinción se diluya totalmente; si tomamos en serio la posibilidad que señala esta objeción, para diluir la distinción y mostrar la identidad (entre la realidad que vemos a través de los lentes y ésta tomada independientemente de nuestros lentes, usando la metáfora de Körner), nos veríamos obligados a dar cuenta de

of Pure Reason, Macmillan Press, Londres, 1979, p. 113). Años más tarde, en 1935, Paton reformula la misma objeción en los siguientes términos: "Aceptando que por medio de nuestras intuiciones puras de espacio y tiempo podemos conocer a priori las condiciones o formas de todos los fenómenos ¿por qué no habría de suceder que espacio y tiempo fueran cosas reales, condiciones o formas de las cosas como nos aparecen, al mismo tiempo que condiciones o formas de las cosas como son en sí mismas?" (Kant's Metaphysic of Experience, vol. I, Humanities Press, Nueva York, 1970, p. 174). Hay un artículo reciente que cuenta con mucho detalle las diversas versiones de esta objeción: F. Xavier Chenet, "Que sont donc l'espace et le temps? Les hypothèses considérées par Kant et la lancinante objection de la 'troisième possibilité'" (Kant-Studien, vol. 84, no. 2, 1993, pp. 129-153). 
un paralelismo o una armonía que no tendríamos manera de fundamentar -aunque tampoco de excluir totalmente. Además, la idea de que el espacio y el tiempo son formas de nuestra sensibilidad parece salir sobrando, porque si son propiedades de las cosas, independientemente de nuestra percepción, ¿qué sentido tiene, además, atribuirlas a la constitución subjetiva? De hecho, Kant pensó que su alternativa resolvía problemas que una postura como la de Newton (que concebía el espacio y el tiempo como seres reales) dejaba abiertos. Volver a incluir la posibilidad de su realidad absoluta no haría sino duplicar los problemas: por un lado, habría que explicar en qué sentido son reales y, por otro, en qué sentido son subjetivos. Podría ser entonces "lógicamente posible" que se diera tal posibilidad, pero sería epistémicamente más difícil explicarla. A lo largo de este trabajo, vuelvo sobre esto de una u otra manera.

Así entonces, podemos aceptar que en cierto sentido, al menos, la distinción entre realidad fenoménica y realidad en sí es una consecuencia del argumento citado más arriba y ocuparnos de dicho argumento. En él se ensañan gran parte de los comentaristas kantianos, y más especialmente Strawson. Para este autor, la tesis de la subjetividad es innecesaria y "fértil en paradojas": por un lado, impregna el concepto de a priori con una oscura carga psicologista innecesaria. Las condiciones a priori propuestas podrían interpretarse de forma austera, sólo en tanto condición de posibilidad. Por otro lado, la tesis de la subjetividad conlleva la distinción, finalmente incoherente, entre fenómeno y cosa en sí: se afirma que aquello que percibimos es sólo fenómeno, pero también se dice que para que exista dicho fenómeno se requiere la materia y, por ende, se requiere que el objeto en sí mismo me sea dado. ${ }^{4}$

Ahora bien, para defender a Kant contra estas objeciones, exploro criticamente algunas de las interpretaciones recientes que se han dado para explicar este deslizamiento hacia la subjetividad. Entre ellas, retomo primero la lectura tradicional que ve el argumento kantiano básicamente como una salida para evitar los problemas que se le plantean a la concepción de Newton. En segundo lugar, está el intento por defender el argumento kantiano apelando a los resultados de la "exposición metafísica" tal y como Kant parece haberlo pensado originalmente, defensa que desarrolla cuidadosamente Henry Allison. En tercer lugar, recojo la interpretación de Paul Guyer, para quien Kant no podría dar su tradicional paso al idealismo sin apoyarse en una premisa adicional: el carácter sintético a priori de las proposiciones de la geometría (perspectiva que, parcialmente, comparte Strawson). La cuarta reconstrucción es de Patricia Kitcher, quien ha encontrado una explicación adicional al insertar la Estética trascendental en una discusión

${ }^{4}$ Cfr. P.F Strawson, Los límites del sentido, trad. Carlos Thiebaut, Revista de Occidente, Madrid, 1972, pp. 43-65 y 222-227. 
candente de aquella época sobre la percepción de las distancias. Por último, recojo conclusiones: por un lado, los intentos por reforzar el argumento de Kant resultan finalmente insuficientes: el idealismo no es una conclusión obligada aunque sí es una hipótesis fructífera para resolver otros problemas; por otro lado, el análisis de dichas interpretaciones me sugiere que la concepción kantiana acerca del espacio resulta más defendible si, en vez de asociarla a Newton, la alejamos de él.

\section{La interpretación tradicional}

Para entender el argumento de Kant conviene asomarse al contexto de la discusión sobre el espacio y el tiempo, donde tanto Leibniz como Newton tienen mucho que decir. Por una parte, Newton pugna por un espacio y un tiempo vacíos y absolutos que existen a manera de contenedores de todo lo real: "el tiempo absoluto, el verdadero y el matemático de suyo y por su propia naturaleza fluye igualmente sin relacionarse con nada" y "el espacio absoluto, sin relacionarse con nada externo, permanece siempre semejante e inamovible en su propia naturaleza". ${ }^{5}$ Por su parte, Leibniz piensa que el espacio y el tiempo no existen sino en tanto relaciones entre cosas; el intento por abstraer las coordenadas espacio-temporales de las cosas no genera sino una idea confusa, difícilmente separable de lo demás: el espacio "es algo meramente relativo como lo es el tiempo", "un orden de coexistencias como el tiempo es un orden de sucesiones". ${ }^{6}$

Pero veamos más de cerca algunas consecuencias de estas dos posturas, que Kant considera las alternativas a partir de las cuales definir su propia concepción acerca del espacio y del tiempo. La postura de Newton convierte el espacio en una entidad que existe con independencia de los objetos materiales en él ubicados, y que como tal —dice Elia Nathán- "tiene un conjunto de propiedades o una estructura propia, que es independiente de la existencia y propiedades de los objetos materiales".? Para Leibniz, en cambio, el espacio no es sino un conjunto de relaciones espaciales que guardan los objetos, por lo cual carece de sentido asignar cualquier propiedad al espacio, ${ }^{8}$ las propiedades espaciales son propiedades de los cuerpos (distancias y relaciones entre ellos) porque sólo hay espacio donde hay cuerpos.

Sabemos que Kant fue partidario de Newton en 1768, cuando escribe "El fundamento de las diferencias de dirección en el espacio", donde aduce que sin referencia a un espacio absoluto, no podríamos dar cuenta del

5 Newton, Principia. Citado por S. Kömer, op. cit., p. 31.

6 Leibniz, "Tercera carta a Clarke". Citado por Kömer, op. cit., p. 31.

7 Cfr. Elia Nathán, "Notas sobre el concepto de espacio absoluto", en E. Villanueva (comp.), Tercer Simposio Internacional de Filosofía, UNAM, México, vol. I, p. 143. Entre dichas propiedades están para Newton, propiedades electromagnéticas, dinámicas y geométricas.

8 Cfr. ibid., p. 144. 
fenómeno de las réplicas incongruentes como los guantes o las manos que, pese a que las relaciones espaciales entre sus partes son las mismas, no pueden ocupar el mismo espacio. Sin embargo, dos años más tarde, en la Disertación inaugural, Kant está preocupado en usar dicho ejemplo con otro propósito: el fenómeno de las réplicas incongruentes no podría explicarse si no aceptamos que el espacio es una intuición y no un concepto. ${ }^{9}$ Hay claros indicios de que Kant estaba en proceso de estructurar una concepción propia sobre el espacio. No obstante, de acuerdo con esta primera lectura, en la Crítica, Kant básicamente sigue siendo newtoniano, sólo que no retoma la concepción de su maestro sin antes darle el fundamento filosófico del que carece, de aquí que básicamente dedique las exposiciones metafísica y trascendental a rebatir, con diferentes argumentos, la concepción de Leibniz. Y es sólo después de esto - de acuerdo con esta primera lectura- que Kant se demarca también con respecto a Newton y rechaza la realidad absoluta del espacio y el tiempo, aunque ello tenga un precio tan elevado como el idealismo y su siempre estorbosa consecuencia de la distinción entre fenómeno y cosa en sí. A la necesidad de encontrar una postura intermedia, que evite las desventajas de las concepciones de Newton y Leibniz, alude este párrafo al final de la Estética:

Quienes, por el contrario, sostienen la realidad absoluta del espacio y el tiempo, sea como subsistente, sea como inherente, tienen que estar en desacuerdo con los principios de la misma experiencia. En efecto, si se deciden por lo primero (partido que suelen tomar los que [como Newton] investigan matemáticamente la naturaleza), se ven obligados a admitir dos no-seres eternos y subsistentes por sí mismos (espacio y tiempo) que existen (aunque no exista nada real) sólo para contener en sí todo lo real. Si se deciden por lo segundo (partido que toman algunos metafísicos [como Leibniz] que estudian la naturaleza) y consideran espacio y tiempo como relaciones entre fenómenos (coexistentes o sucesivos), como relaciones abstraídas de la experiencia, si bien confusamente representadas en tal separación, tienen que negar la validez, o al menos la certeza apodíctica, a las doctrinas matemáticas a priori respecto de las cosas reales (por ejemplo, en el espacio). (B 56-57)

En una primera lectura, diríamos que es la necesidad de ahorrarse el problema ontológico de explicar de qué forma existen un espacio y un tiempo absolutos lo que lleva a Kant a optar por el idealismo, es decir, a concebir las formas como parte de nuestra "estructura sensible", a manera de

9 Cfr. Disertaciones latinas de Kant, trad. J.D. Garcia Bacca, Universidad Central de Venezuela, Caracas, 1974, pp. 39-41. Al respecto de esto véase también un artículo de J. Bennett, "The Difference between Right and Left", American Philosophical Quarterly, vol. VII, 1970, y la discusión de Allison en El idealismo trascendental de Kant, urad. D.M. Granja, UAMLÁnthropos, México/Barcelona, 1992, pp. 168-171. Hay también una excelente tesis de maestría sobre las consecuencias filosóficas del problema de las contrapartes incongruentes de Julio Beltrán, que conviene consultar a quien quiera extenderse en este punto. 
unos lentes que siempre llevamos puestos. Esta alternativa da cuenta de la validez general a priori de dichas formas, ya que en tanto estructuras de aprehensión, filtran todo aquello que nos es dado y, al mismo tiempo, evitan lidiar con la realidad objetiva de tales entidades, ya que "no son nada para nosotros" fuera de nuestra facultad sensible. Sin embargo, no es claro que la alternativa de Kant no plantee un problema ontológico peor que el que se resuelve (o evade), ya que considerarlas como subjetivas implica -para Kant - un concepto dividido de realidad: por un lado, la realidad sujeta a dichas condiciones amenaza con convertirse en un juego de representaciones; por otro, la realidad independiente de nuestras formas queda a manera de una existencia fantasmal que amenaza con incongruencias el resto de la filosofía kantiana. Además, la opción de referir las formas a la estructura subjetiva implica la pregunta de cómo es que dicha estructura es de tal manera: ¿es una cuestión evolutiva o genética?, ¿es una capacidad o una disposición innata? La perspectiva kantiana parece abrir más interrogantes de las que cierra. Podemos entender que Kant quisiera demarcarse de Newton y optara por el idealismo, pero no podemos aceptar que esto baste para justificar dicha inferencia.

\section{La propuesta de Allison}

Henry Allison está de acuerdo en que Kant busca una postura intermedia entre la concepción relacional del espacio de Leibniz y la concepción absoluta de Newton. La idea del espacio como una condición subjetiva -como forma de nuestra aprehensión - resuelve, para Kant, los problemas de las otras dos concepciones, conservando sus ventajas. Según Allison, esta concepción del espacio está demostrada básicamente en la exposición metafísica que antecede al famoso argumento en favor de la subjetividad. El paso no depende de premisas adicionales ni consiste él mismo en un brusco alejamiento de Newton, ya que aunque los argumentos de la exposición metafísica están pensados fundamentalmente contra Leibniz, implican resultados que son incompatibles con la concepción de Newton. ${ }^{10}$ Dichos argumentos estructuran y dan solidez a la tesis del espacio como "forma de la intuición". Pasemos entonces a analizar con más detalle dichos argumentos, el primero de ellos dice así:

El espacio no es un concepto empírico sacado de experiencias externas. Pues para que ciertas sensaciones sean referidas a algo fuera de mí (es decir, a algo en otro lugar del espacio que el que yo ocupo), y asimismo para que yo pueda representarlas como fuera y al lado unas de otras, por tanto no sólo como distintas, sino como situadas en distintos lugares, hace falta que esté ya a la base la representación del espacio. (G.M. B 38-39) 
Como bien se ha señalado, ${ }^{11}$ el argumento de Kant parece tautológico, ya que afirma que no podríamos conocer las cosas que ocupan diferentes lugares del espacio sin presuponer el espacio, es decir, Kant (entre paréntesis) parece especificar que por "algo fuera de mî" está entendiendo "ocupa un lugar diferente en el espacio", con lo cual vuelve su argumento trivial. Sin embargo, como bien señala Allison, el argumento puede leerse como si dijera: el espacio es un criterio necesario para reconocer objetos distintos de mí y distintos entre sí. Sin el espacio, es decir, sin situarlos en lugares distintos, no podríamos hablar de objetos diferentes. ${ }^{12}$ Podríamos, entonces, reformular el argumento a la manera de Allison: la representación del espacio "funciona en la experiencia humana como una condición de posibilidad necesaria para distinguir los objetos unos de otros". ${ }^{13} \mathrm{El}$ argumento, más que una implicación analítica es una relación de presuposición. Además, es posible que seres distintos de nosotros tuvieran criterios para diferenciar objetos que no se apoyaran en el espacio. La propuesta de Allison es atractiva: el espacio funciona como un criterio de diferenciación de objetos externos. Cabe notar, sin embargo, que ello puede mantenerse tanto desde una postura absolutista como de una relacional: distinguimos objetos con las mismas propiedades sensibles por el lugar que ocupan, ya sea respecto a su posición en el espacio absoluto, ya sea respecto a su posición entre otros objetos. En el nivel cotidiano, nos orientamos igual si el espacio es absoluto o relacional; la reformulación que fortalece el argumento kantiano le quita -me parece- su carácter contra Leibniz; para diferenciar objetos externos requerimos del espacio, pero no se requiere - al menos sin un argumento adicional- que sea un espacio absoluto. Paso al segundo argumento, que Kant formula así:

El espacio es una representación necesaria, a priori, que está a la base de todas las intuiciones externas. No podemos nunca representarnos que no haya espacio, aunque podemos pensar muy bien que no se encuentran en él objetos algunos. Es considerado, pues, el espacio como la condición de la posibilidad de los fenómenos y no como una determinación dependiente de éstos. (G.M. B 38-39)

11 Véase, por ejemplo, Strawson, op. cit., p. 53.

12 La argumentación de Allison se basa en cómo interpretar el término alemán ausser (fuera de...) en dicho párrafo. La traducción de Kemp Smith (asi como las dos versiones españolas) dan un sentido espacial al término que, de acuerdo con Allison, no tiene en este contexto. De cualquier manera, la tesis de Allison la apoya Guyer, quien dice que si comparamos dicho argumento con su versión en la Disertación inaugural podemos afirmar que lo que Kant quiso decir es que "los objetos no pueden ser representados distintos unos de otros, 0 del sujeto, a menos que sean representados como si ocuparan diferentes lugares en el espacio" (Paul Guyer, Kant and the Claims of Knowledge, Cambridge University Press, 1987, p. 346). La traducción de García Bacca de la Disertación inaugural (p. 39) no refleja este contraste.

13 Allison, op. cit., p. 145. 
Parece natural pensar que Kant se refiere a una imposibilidad psicológica: no podemos imaginar cosas sin espacio, pero sí espacio sin cosas. Esta lectura suele respaldarse en el hecho de que Kant recurra a un experimento para defender el carácter a priori: pensemos en un objeto y vayamos despojándolo de sus propiedades; primero sensibles, como dureza, color, peso, etc.; luego quitemos "lo que el entendimiento piensa de él", como sustancia, divisibilidad, etc.; lo que queda, dice Kant, es sólo su figura y su extensión. Mediante un Gedankenexperimente damos con las cualidades primarias de un objeto. ${ }^{14}$ Pero esto, como bien se ha señalado, no es evidente. Dice Strawson, con razón, que al imaginarnos un espacio vacío no es claro si nos imaginamos algo, y más adelante señala que al despojar a los cuerpos de todas sus propiedades, no es claro que nos quedemos con "extensión y figura", en vez de con palabras sin sentido. ${ }^{15}$

Allison replica que Kant no pretende apoyarse en una verdad lógica, ya que siempre señala que puede haber otras formas de representación, pero tampoco en una tesis psicológica acerca de lo que podemos o no imaginar. Lo que Kant pretende es hacer del espacio una condición epistémica. El argumento se vuelve más claro si pensamos, sugiere Allison, en qué sentido va contra Leibniz, y para ilustrarlo retoma la objeción de Maas a la tesis kantiana: ${ }^{16}$ la idea de Maas es que un leibniziano puede aceptar que el carácter espacio-temporal que presentan los objetos $(B)$ es algo distinto de los objetos mismos $(A)$, y aceptar que los objetos $-A-$ no pueden darse sin su carácter espacio-temporal $B$, sin por ello aceptar que $B$ sea a priori: siempre nos es dado $A B$, y $B$ puede separarse sólo en tanto lo abstraemos de $A B$. Creo que Kant aceptaría que en cierto sentido Maas tiene razón: lo que nos es dado es siempre $A B, A$ no puede darse solo, y tampoco $B$ (un espacio único, vacío e ilimitado no es un objeto posible de experiencia pues carece de materia), sólo que esto no convierte el carácter espacio-temporal en una propiedad más de los objetos, como pensaría el leibniziano; $B$ no es sólo parte de $A B$, sino además es condición de posibilidad de $A$ : la pretensión de Kant es que la percepción de objetos es posible sólo si está enmarcada en un único ámbito espacio-temporal que por sí mismo carece de contenido. El argumento de Kant podría reformularse diciendo que para representarnos cualquier orden específico entre cosas, es necesario presuponer la representación del espacio.

Me parece que aquí el argumento de Allison no es tan afortunado, pues no logra despejar en qué sentido el espacio vacío es una condición para representar un orden específico; siempre podría suceder, como pensaba

14 Véase, respecto al experimento, B 35, y respecto a la espacialidad como propiedad primaria, A 28.

15 Strawson, op. cit., pp. 53 y 55.

16 Cfr. Allison, op. cit., pp. 146 y 151. 
Leibniz, que son las relaciones espaciales entre objetos lo que hace posible hablar del espacio. Al parecer, no se trata de que nos representemos un espacio vacío donde ubicar cosas, pero entonces, ¿en qué sentido el espacio es una representación necesaria y distinta de las relaciones específicas entre objetos?, ¿en qué sentido el Espacio es distinto de la espacialidad de los objetos? Conceder independencia al Espacio entra en tension -como ya se ha señalado $-{ }^{17}$ con resultados posteriores de la Analítica, según los cuales nuestras concepciones del espacio y el tiempo dependen de nuestra experiencia de objetos relacionados causal y dinámicamente, de tal manera que no podemos percibir directamente el espacio o el tiempo; pero, ¿cómo interpretar este argumento para evitar tensiones? Quizá el malestar y las dudas que siembran estas preguntas aminoren cuando pasemos a los últimos argumentos, donde el espacio se perfila como "intuición pura".

Los dos últimos argumentos de la exposición metafísica pretenden demostrar que el espacio es una intuición y no un concepto. El tercer argumento dice así:

El espacio no es un concepto discursivo o, como se dice, un concepto universal de relaciones entre cosas en general, sino una intuición pura. En efecto, ante todo sólo podemos representarnos un espacio único. Cuando se habla de muchos espacios, no se entienden por tales sino partes del mismo espacio único. Estas partes tampoco pueden preceder al espacio único y omnicomprensivo como si fueran, por así decirlo, elementos de los que se compondría, sino que solamente pueden ser pensadas dentro de él. El espacio es esencialmente uno. Su multiplicidad y, por tanto, también el concepto universal de espacio, surge tan sólo al limitarlo. (B 39)

Lo que pretende Kant básicamente en este argumento, sugiere Allison, es mostrar que el espacio se comporta de manera diferente que los conceptos: por una parte, la relación que hay entre el Espacio y los espacios es diferente de la que hay entre un concepto y su extensión, en el último caso los particulares caen en el concepto general pero no son "parte de él" (por ejemplo, los gatos, tigres, etc., caen bajo el concepto de 'felino' pero no son partes de un felino único), los espacios, en cambio, sí son parte de un único espacio original. Por otro lado, la relación entre el Espacio y los espacios es también diferente de la de un concepto general y su intensión, ya que en esta última son los conceptos particulares - de mayor intensión- los que incluyen el concepto general (por ejemplo, el concepto de mamífero incluye el de vertebrado y éste el de ser vivo), mientras que respecto al Espacio, es éste el que incluye a los espacios particulares. Los conceptos empíricos, además, son resultado de una abstracción a partir de un conjunto o una colección de particulares, el Espacio, en cambio, no es el resultado de la 
suma de los espacios particulares, sino que él mismo es un particular y está dado como una totalidad a partir de la cual - por limitación - delimitamos otros espacios. ${ }^{18} \mathrm{El}$ espacio es, pues, único y el ser algo particular lo convierte en una intuición. El último argumento agrega la idea de que el espacio es, además, infinito:

El espacio se representa como una magnitud dada infinita. Se debe pensar cada concepto como una representación que está contenida en una infinita cantidad de diferentes representaciones posibles (como su característica común) y que, consiguientemente, las subsume. Pero ningún concepto, en cuanto tal, puede pensarse como conteniendo en sí una multitud de representaciones. Así es, no obstante, como se piensa el espacio, ya que todas sus partes coexisten ad infinitum... (B 40) ${ }^{19}$

Kant -y Allison - vuelven al contraste con el concepto, el cual es ilimitado respecto a su extensión, pues siempre puede calificar nuevos elementos, pero no respecto a su intensión, ya que un número ilimitado de notas convierte un concepto en ininteligible; el espacio es, en cambio, un particular dado ilimitado (que puede contener un número infinito de partes). ${ }^{20}$ Pero, otra vez, ¿en qué sentido tenemos la representación de un espacio ilimitado?, ¿significa que el espacio ilimitado es un objeto que podemos intuir? Kant niega esto: el espacio vacío carece de materia, no hay nada en él que nos afecte sensiblemente; de aquí que el espacio no sea un objeto o una propiedad de los objetos, sino unas coordenadas donde ubicar objetos. Kant opta por concebir el espacio como una intuición pura, es decir, una intuición formal que carece de materia. Pero, icómo es posible una intuición pura, una particularidad sin contenido? De acuerdo con Allison, contestar esto nos da una clave para entender el argumento de la subjetividad del espacio; si logramos entender cómo puede ser dado el espacio sin ser por ello un objeto de intuición, lograremos ver en qué sentido Kant comienza a dejar a un lado la concepción de Newton para dirigirse al idealismo.

Me alejo un momento de la lectura de Allison para entender el distanciamiento de Kant con respecto a Newton retomando una sugerencia de Bennett: él dice que para Kant el espacio se parece más a un nombre propio que a un concepto general. Se comporta más como "Immanuel Kant" (que designa un particular) que como "un gran filósofo alemán". ${ }^{21}$ Sin embargo,

18 Cfr. Allison, op. cit., pp. 155-156.

19 Este argumento cambia sustantivamente de una edición a otra: cfr. A 25, argumento 5. Cabe señalar que, para evitar incongruencias con la Dialéctica, debe entenderse por infinito "ilimitado", un infinito potencial, más bien que un infinito actual.

${ }^{20}$ Cfr. Allison, op. cit., pp. 158-159.

21 Cfr. Jonathan Bennett, La Crítica de la razón pura de Kant. 1. La Analítica, trad. A. Montesinos, Alianza, Madrid, 1966 (Alianza Universidad), pp. 86-87. 
Bennett no se da cuenta de que la analogía con el nombre propio tiene un límite, ya que para Kant el espacio no designa ningún particular objetivo (real o posible) como sí pretende hacerlo el nombre propio; el espacio designa una forma o carácter general de todo objeto externo real o posible. Es Newton, por así decirlo, quien consideraría el espacio y el tiempo como nombres propios, etiquetas que designan dos particulares objetivos (reales, en su caso). Kant rechaza que sean nombres propios, ellos son condiciones no sólo para determinar la extensión de un concepto general, sino también para determinar el referente específico de un nombre propio, cuando éste se refiere a un objeto externo. Son un armazón, una estructura fundamental donde ubicar y reubicar objetos. Podemos considerar tal estructura y preguntarnos acerca de sus propiedades, pero para hacer una ciencia del espacio tenemos que hacer geometría. Las propiedades geométricas del espacio -como la tridimensionalidad o su carácter euclídeo- surgen cuando examinamos el espacio a manera de un concepto, es decir, cuando lo consideramos como una estructura donde representar y construir objetos geométricos, lo cual - sugiere Kant más adelante (en una nota a B 161) - requiere convertir la forma de la intuición en el contenido de un concepto abstracto: el espacio como objeto de estudio y reflexión. Es decir, el espacio como objeto de la geometría se vuelve el nombre de una estructura donde construir, mediante definiciones, objetos geométricos; mientras que el espacio como intuición se refiere a un carácter general que presentan las representaciones y que les está dado por su ubicación en un armazón perceptual único. El espacio como intuición es también un armazón, pero no un armazón donde construir objetos a partir de definiciones, sino una estructura donde ubicar y reubicar sensaciones para que conformen un ámbito de intuiciones. El espacio es un criterio fundamental básico para una tarea obligada de todo conocimiento: diferenciar objetos externos. Volviendo a la sugerencia de Bennett: podríamos decir que es un nombre, pero precisamente no un nombre como "Immanuel Kant", sino más bien el nombre de una estructura de ubicación y reubicación. De esta forma, la discrepancia fundamental con Leibniz sería no tanto que el espacio sea relacional (puesto que la ubicación y reubicación podrían definirse en función de relaciones), sino que dicho orden sólo pudiera ser "confusamente abstraído" de la experiencia. Para Kant, la función epistémica que desempeña el espacio en la experiencia hace sospechar que no es sólo una propiedad o relación empírica más; el espacio no es un orden específico, sino un conjuntos o ámbito de órdenes posibles.

Por su parte, Allison piensa que el carácter de "dado" pero no empírico apunta a la idea de una estructura preconceptual, el espacio es una "preintuición", es decir, el espacio "es dado junto con toda intuición determinada 
como su fundamento o condición original". 22 Pero, ¿qué es lo que hace que el espacio tenga un papel tan privilegiado en nuestra percepción?, ¿qué es lo que hace que pueda ser "separado" y no sólo "confusamente abstraído" de lo percibido? La única razón que encuentro en Kant, y en Allison, nos remite al primer argumento: el espacio funciona como condición de posibilidad de los objetos en el sentido de que ofrece un criterio de reconocimiento de la particularidad y la especificidad de los objetos. Es el primer argumento - en todo caso complementado con el tercero- lo que constituye, me parece, la fuerza de la exposición metafísica y, consiguientemente, la fuerza de la defensa de Allison.

Los argumentos posteriores -el tercero en particular-alegan que el espacio no se "comporta" como un concepto sino como una intuición ya que se refiere a algo único, sólo que a diferencia del nombre propio no designa un objeto sino una forma de los objetos. Este argumento es vago; sin embargo, resulta especialmente interesante si se ve como complemento del primero: si el espacio no fuera único, no funcionaría como criterio de diferenciación de objetos. Y aquí cabe recoger una objeción usual al tercer argumento, de la que podríamos zafarnos relativamente si apelamos al primero: es posible que nuestra experiencia pasara alternativamente de un espacio a otro sin que nosotros pudiéramos establecer una ruta para conectarlos; en la literatura española, esta posibilidad está ilustrada parcialmente en La vida es sueño de Calderón de la Barca. Siguiendo su idea, imaginemos un personaje que habita alternativa, pero sistemáticamente, en ámbitos completamente diferentes, y no sabe cómo llegar de uno a otro; hace todo lo posible por encontrar una conexión espacial entre ambos pero no lo logra, y llega a concebir que está alternativamente en espacios distintos. ${ }^{23}$ Con base en el primer argumento, podríamos preguntarnos si nuestro personaje sería capaz de reidentificar un objeto que aparezca en ambos ámbitos - digamos un anillo-como el mismo objeto. Si reidentifica tal objeto como el mismo, entonces parece estar obligado a suponer que existe alguna ruta que conecta ambos espacios y por la cual dicho objeto "transita" de uno a otro y, por ende en este sentido, que ambos espacios tienen un único espacio de trasfondo. Por otra parte, si nuestro Segismundo no reidentifica el objeto como el mismo, entonces se verá obligado a dudar de la identidad de su propio cuerpo (si el anillo no es el mismo, ¿por qué sí lo es el cuerpo que adorna?) y, con ello, probablemente de su propia identidad mental. Parece claro que, si el espacio no es único, la reidentificación de objetos se en-

22 Allison, op. cit., p. 161.

23 La objeción -en diferentes versiones-es retomada por J. Bennett, op. cit., pp. 88-89; por T.E. Wilkerson, Kant's Critique of Pure Reason, Clarendon Press, Oxford, 1976, pp. 29-35, y por José de Teresa, "El espacio, simple forma de nuestra sensibilidad", Signos, UAM-I, México, 1989, pp. 220-221. La referencia a la obra de Calderón de la Barca me fue sugerida por un texto de Ulises Moulines, quien, sin embargo, lo cita con otro propósito. 
torpece. De cualquier manera, un análisis detallado de esta objeción nos obligaría a recurrir a elementos posteriores de la Crítica -las analogías, la refutación al idealismo-, lo cual muestra que la unicidad del espacio no es condición suficiente de reconocimiento, sino sólo condición necesaria. Lo que tenemos es que el espacio, en tanto una coordenada única donde ubicar objetos, se perfila como condición necesaria para el reconocimiento de particulares; es esto - 0 al menos debería ser- lo que podemos entender por "intuición pura": algo que se perfila como un rasgo necesario de los objetos externos. Hasta este punto, cabe señalar que no hay un compromiso explícito con el idealismo: lo que se afirma es que el espacio es una condición obligada, una forma invariante de toda representación, los objetos deben adquirir este carácter y los sujetos deben apuntalar sobre este carácter uno de los rasgos más básicos de su experiencia. Ambos dependen, por así decirlo, de esta condición y no es claro quién la impone. Ahora bien, ¿cómo pasar del espacio como "intuición pura" al espacio como "forma de la subjetividad"?, ¿cómo pasar de una condición del conocimiento y sus objetos a una condición impuesta por el sujeto?

Lo que Kant necesita, dice Allison, es un argumento puente entre los resultados de su exposición metafísica y la alternativa idealista, y Allison piensa que dicho argumento está sugerido en los Prolegómenos. Es aquí donde Kant se pregunta claramente cómo puede preceder la intuición al objeto, ${ }^{24} \mathrm{e}$ inmediatamente después afirma que si dicha intuición representara algo en el objeto no podría ser a priori ya que dependería de mi percepción, por consiguiente, para ser a priori la intuición deberá ser pura, es decir, no contener nada empírico. Kant concluye que la intuición sólo es pura si no contiene más que la forma de la sensibilidad. ${ }^{25} \mathrm{El}$ argumento puente establece una equivalencia que respalda el confiado "manifiestamente" que usa Kant en el argumento que citamos en las primeras páginas: la intuición es pura si, y sólo si, no representa sino una forma subjetiva. Allison confía en que dicha equivalencia puede respaldarse en la exposición metafísica (tal y como él la ha defendido atrás), y en ello consiste su peculiar originalidad. Reconstruyo brevemente su análisis de los dos condicionales que incluye dicha equivalencia y evalúo a mi juicio sus conclusiones.

El primer condicional, que supone que algo es una forma de la subjetividad y de ahí pretende explicar que pueda ser una intuición pura, es relativamente sencillo de demostrar a la luz de la exposición metafísica. En primer lugar, habría que señalar que por "forma de la sensibilidad" puede entenderse o bien una forma de intuir, es decir, algo así como un mecanismo subjetivo de percepción, o bien una forma de lo intuido, es decir, una forma que los objetos percibidos adquieren en virtud de ser intuidos. De cualquier

24 Kant, Prolegómenos, $\S 8$ al final.

25 Cfr. Prolegómenos, $\$ 9$. 
manera, si una intuición representa sólo una condición preconceptual de nuestra percepción (una forma de intuir), o una forma de los objetos en tanto ellos son intuidos por nosotros (forma de lo intuido), entonces es una intuición a priori, ya que es anticipada por la conciencia y no se refiere a algo en el objeto (sino sólo a algo que éste adquiere en virtud de ser intuido). En particular, si el espacio es una forma obligada para los humanos de percibir objetos, si el espacio es un filtro de nuestra conciencia, entonces los objetos, para ser percibidos y reconocidos como objetos distintos, tienen que pasar por dicho filtro, y poseerán su carácter espacial a manera de una particularidad pero anticipada por la conciencia, es decir, su espacialidad será una intuición a priori. ${ }^{26}$

El segundo condicional, que pretende que una intuición sólo es posible a priori si representa una forma de la percepción humana, es mucho más complejo. Aquí se pretende demostrar que ser una "forma de la sensibilidad" - o una "forma de la intuición" - no sólo es condición suficiente, sino además necesaria para que algo sea una intuición pura. Allison dice que aquí es donde Kant pretende mostrar justamente la superioridad de su perspectiva frente a las concepciones de Newton y Leibniz. Si alguna de estas perspectivas diera cuenta del espacio como una intuición pura, entonces la alternativa idealista no sería la única solución. Pero esto no se cumple: la concepción relacional del espacio no da cuenta de su carácter a priori y lo convierte en una relación empírica; de acuerdo con Allison, Leibniz no se da cuenta de que el espacio es una condición para diferenciar objetos más bien que una relación más entre ellos. ${ }^{27}$ La concepción absoluta, por su parte, tampoco da cuenta de esto, pues aunque considera que el espacio puede separarse de los objetos y ser a priori en este sentido, no acepta el hecho de que por sí mismo no representa ningún objeto adicional; Newton considera el espacio como algo en sí mismo, cuando sabemos que no es sino una condición de diferenciación y reidentificación de objetos. Y si esto es así, concluye Allison, entonces Kant no descuidó la tercera opción que mencionan Kemp Smith, Paton, Körner y muchos más, ya que el problema de considerar a la vez el espacio como forma subjetiva y como propiedad de las cosas en sí es que en tanto propiedad de las cosas seguiría presentando los mismos problemas que presenta la concepción newtoniana, además de que introduciría un problema adicional: explicar cómo es que el espacio real coincide con el espacio como "forma de la subjetividad". ${ }^{8}$

26 Cfr. Allison, op. cit., pp. 176-178.

27 Además, la otra razón contra Leibniz, según la cual tendría que considerar las proposiciones geométricas como puramente sintéticas, entra en conflicto con su aceptación explícita de que la geometría es analítica y sus proposiciones son verdades de razón. Agradezco a Alejandro Herrera esta observación.

${ }^{28}$ Cfr. Allison, op. cit., pp. 179-184. 
Pero aquí cabe detenerse para recoger la continua queja de Strawson: no es claro que si Kant habla de condiciones de nuestra percepción no hable de estructuras cognoscitivas sujetas, por ejemplo, a un estudio psicológico (o a la evolución). En tal caso las condiciones serían subjetivas pero empíricas y parecería que, como señala Strawson, Kant estaría respaldando su noción de a priori con una tesis psicologista ${ }^{29}$ Allison menciona que Kant no pretende esto, su concepto de "forma de la sensibilidad" no equivale a "estructura innata". Kant -nos recuerda insistentemente Allison-no pretende establecer condiciones psicológicas —o biológicas- sino epistémicas. Pero entonces, ¿por qué hacer del espacio una forma de la sensibilidad, además de una intuición pura, cuando ser una "intuición pura" ya recogía su carácter de condición epistémica? Kant no consideraba el espacio "innato", me parece, porque lo concebía como una forma o mecanismo de percepción más bien que como una representación con contenido propio; sin embargo, pensar en "formas" cuyo asiento está en el espíritu humano (formas o mecanismos de intuir) es otra forma de pensar en algo innato, sólo que quizá más cercana a Chomsky que a Descartes. Kant pudo haberse quedado con la idea del espacio como una "intuición pura" en el sentido que especifiqué atrás: un espacio único es condición necesaria de la diferenciación y reidentificación de objetos, sin preguntarse por cuál concepción metafísica - si la absolutista de Newton, la relacional de Leibniz o la idealista propuesta por él- daría mejor cuenta de esto. Si Kant rechazaba la idea del innatismo porque consideraba que era una hipótesis explicativa innecesaria, también pudo rechazar la teoría de las formas de la subjetividad por las mismas razones. Pese a los heroicos intentos de Allison, me parece que la sugerencia de Strawson continúa en pie: siempre podemos quedarnos con una interpretación austera del a priori, sólo en tanto condición de posibilidad, sin buscar un apoyo adicional. ${ }^{30}$

\section{La propuesta de Guyer}

Es curioso que en la primera edición de la exposición metafísica del espacio, Kant haya introducido un tercer argumento adicional para demostrar su carácter a priori: si el espacio fuera una representación a posteriori, no podríamos explicar el carácter a priori de las proposiciones de la geometría, y la idea, por ejemplo, de que el espacio es tridimensional sería sólo una

29 Al convertirse en algo psicológico serian igualmente obligadas (mientras sean vigentes), pero estarian sujetas a variaciones. Kant rechaza esta interpretación (el pasaje más claro con respecto a las categorías es $B$ 167-168), pero como veremos más adelante, Kitcher muestra que esta interpretación tiene más atractivos que los que Strawson le concede.

30 Me parece que en su libro Individuals, Strawson hace un uso austero de ciertos resultados de la Estética al reconocer que un criterio para la identificación y reidentificación de particulares es suponer un único ámbito espacio-temporal. 
verdad contingente, apoyada por inducción en nuestra experiencia perceptual. ${ }^{31}$ Ello ha hecho pensar que Kant tiene en realidad una razón adicional -y fundamental- para concluir la subjetividad del espacio: sólo si éste es una forma subjetiva puede explicarse el carácter sintético a priori de la ciencia del espacio. Strawson ${ }^{32}$ y Bennett ${ }^{33}$ han defendido esta interpretación y afirman que, en este sentido, la parte importante de la Estética no es la exposición metafísica sino la exposición trascendental. Es importante señalar, sin embargo, que sus conclusiones al respecto parecen desprenderse del hecho de que ambos consideran que los otros cuatro argumentos (analizados en la sección anterior de este trabajo) son oscuros, tautológicos o falsos.

Paul Guyer busca reformular esta intuición de que es el status de las verdades geométricas lo que resulta finalmente decisivo para aceptar la idealidad del espacio; sólo que Guyer - a diferencia de Strawson o Bennettreconstruye una estrategia de argumentación en vez de apelar meramente a dicho argumento con base en la oscuridad o debilidad de los otros. Guyer no desprecia los argumentos de Kant, sólo ve en ellos una insuficiencia intrínseca: al aceptar los cuatro argumentos de la exposición metafísica lo que se logra, nos dice, es, a lo más, mostrar que la representación del espacio es necesaria para la representación de objetos particulares y que necesariamente nos representamos el espacio como algo único e ilimitado. Pero lo que vale necesariamente para la representación del espacio podría no valer para el espacio mismo, en tanto referente de dicha representación. En el mejor de los casos, Kant ha demostrado cómo debe ser la representación del espacio, pero no que el espacio sea sólo dicha representación, para ello hace falta un argumento adicional. ${ }^{34}$ Me parece que esta acertada objeción es otra manera de recoger la crítica tradicional de la "alternativa desatendida": como

31 Cfr. A 24 -en el caso del tiempo, el tercer argumento no fue eliminado por Kant (cfr. A 31 y B 47).

32 Dice Strawson que el idealismo trascendental descansa en el argumento de la geometría cuya premisa vital es que "las proposiciones geométricas se mantienen necesariamente para los objetos físicos en el espacio" (op. cit., p. 63).

33 Bennett dice que el "único argumento serio" en favor del status de la teoría del sentido externo es el carácter sintético a priori de las proposiciones de la geomerria, y es un argumento que carece de valor, pues: "incluso si únicamente la teoría del sentido externo pudiese explicar que la geometría euclídea tenga el status que Kant cree que tiene, no se sigue que la teoria sea verdadera salvo que dispongamos de una premisa adicional que nos diga que la geometría euclídea es sintética y a priori" (op. cit., p. 38).

34 Textualmente: "Podemos conceder a Kant que poseemos unas representaciones a prio$r i$ del espacio y del tiempo, a partir de las cuales podemos derivar nuestro conocimiento a priori de su unicidad e infinidad; pero, que podemos reducir espacio y tiempo a meras representaciones, o que podemos identificarlas con intuiciones puras más bien que con los objetos de dichas representaciones singulares, es algo que difícilmente se sigue sin un argumento adicional, que muestre que la aprioricidad conlleva subjetividad o idealidad trascendental" (Paul Guyer, op. cit., p. 348). 
señalan Kemp Smith, Paton, Körner, y ahora Guyer, Kant no logra demostrar que la unicidad y la aprioricidad del espacio son suficientes para convertir éste en una mera forma de intuir o en una forma de los objetos sólo en tanto son intuidos; siempre podría suceder que el espacio fuera, además, una realidad en sí o una propiedad real de las cosas en sí. Finalmente, no es claro por qué no concluir el realismo en vez del idealismo.

De acuerdo con Guyer, Kant esgrime básicamente tres razones adicionales para dar este paso: la primera es un argumento metafísico, la segunda un argumento teológico y la tercera, la más profunda, es que la concepción de Kant del conocimiento a priori es incompatible con el realismo. ${ }^{35}$ Cabe señalar que, para Guyer, estos tres argumentos suponen una distinción previa entre fenómeno y cosa en sí: la realidad dicótoma es un supuesto más bien que una consecuencia del idealismo. Ahora bien, el primer argumento, el argumento metafísico, se ubica al final de la Estética y corresponde básicamente al siguiente párrafo de Kant:

Ahora bien, por medio de simples relaciones no se conoce una cosa en sí misma. Hay que concluir, pues, que, desde el momento en que no se nos dan a través del sentido externo más que representaciones de relación, este sentido sólo puede contener en su representación la relación de un objeto con el sujeto, no lo interno, lo que pertenece al objeto en sí mismo. (B 67)

Este argumento parece ponernos en un dilema cuya única salida es el idealismo: por un lado, la espacialidad de los objetos es algo esencial a su representación; por otro lado, ninguna propiedad relacional puede ser esencial al objeto. La forma de conciliar esta tensión es, para Kant, introducir la distinción entre cosa en sí y objeto de representación y pensar que la espacialidad es propiedad esencial de lo segundo pero no así de lo primero. Guyer señala, contra este primer argumento, que Kant está identificando el considerar una cosa absolutamente con el considerarla aislada de lo demás, cuando dicha identidad no es obvia. De acuerdo con Guyer, la creencia de que las propiedades relacionales de un objeto no pueden ser propiedades esenciales es una creencia ampliamente extendida, esto podría explicar el por qué Kant compartía dicha creencia, pero no lo justifica. A pesar del párrafo de Kant citado atrás, no es claro que Kant esté casado con dicha creencia, pues también acepta que el espacio es una propiedad primaria (y en este sentido, esencial). ${ }^{36}$

35 Textualmente: "su concepción de la naturaleza del conocimiento a priori, y específicamente una interpretación de la verdad necesaria como absoluta — más bien que como condicional- que es incompatible con él, por otra parte, supuesto natural de que la restricción de nuestra mente a las representaciones espacio-temporales es evidencia suficiente para la actual espacio-temporalidad de lo que experimentamos" (ibid., p. 349).

36 Cfr. A 28-29. 
El segundo argumento es de carácter teológico y está expresado al final de la Estética. De acuerdo con él, si el espacio y el tiempo fueran propiedades de lo real -y no sólo de lo perceptual-, entonces dichas propiedades deberían inherir en todo lo que fuese real y, en particular, en Dios:

En efecto, como condiciones de toda existencia, deberían serlo también de la existencia de Dios. (B 71)

Pero como para Kant esto es absurdo, ya que Dios no es espacio-temporal, entonces el espacio y el tiempo no son propiedades de lo real sino sólo formas de representación sensible. Guyer objeta que, en este caso, Kant procede a generalizar lo que podría no ser generalizado: decir que el espacio y el tiempo son propiedades de algunas cosas reales, de aquellas cosas que podemos percibir, no nos compromete a decir que sean propiedades de todo lo real, podría haber entidades que no fuesen espacio-temporales. ${ }^{37}$

Sin embargo, para Guyer el argumento importante es el tercero, y consta de dos etapas: por un lado, la concepción kantiana del conocimiento a priori lleva a la tesis de que el espacio no puede ser una propiedad de las cosas en sí; por otro lado, el espacio, al no poder ser una propiedad de las cosas en sí, es considerado como una mera "forma de la sensibilidad humana". ${ }^{38}$ Con el objeto de reconstruir la última etapa, Guyer cita algunos pasajes donde se infiere la subjetividad de las formas a partir de la no espacio-temporalidad de las cosas en sí; uno de ellos de la Estética, justo después de la exposición trascendental del espacio, dice así:

a) El espacio no representa ninguna propiedad de las cosas, ni en sí mismas ni en sus relaciones mutuas, es decir, ninguna propiedad inherente a los objetos mismos y capaz de subsistir una vez hecha abstracción de todas las condiciones subjetivas de la intuición. Pues ninguna determinación, sea absoluta o relativa, puede ser intuida con anterioridad a la existencia de las cosas a las que corresponda ni, por tanto, ser intuida a priori.

b) El espacio no es más que la forma de todos los fenómenos de los sentidos externos, es decir, la condición subjetiva de la sensibilidad. (A 26/B 42) ${ }^{39}$

Si el espacio es una propiedad de todo objeto intuido, y sin embargo (por hipótesis) no es una propiedad del objeto en sí, entonces el espacio debe

37 Cfr. ibid., p. 353.

38 Ibid., pp. 354-355.

39 Para apoyar este orden del argumento véase también Reflexiones $6349,6346,6355$ (citadas por Guyer, pp. 357-358); y Los progresos de la metafisica desde Leibniz y Wolff 266267 (escrito circa 1791, publicado en 1804. Trad. Félix Duque, Tecnos, Madrid, 1987, p. 26). Sin embargo, Guyer no da cuenta de otros pasajes donde la implicación es al revés - de la subjetividad de las formas a la distinción fenómeno/cosa en sí, lo cual hace pensar que, independientemente del orden, las tesis son equivalentes. 
ser una forma de nuestra intuición, es decir, algo que el objeto posee en virtud de ser intuido. Notemos que, en este nivel, la "tercera opción desatendida" queda, de entrada, excluida.

Pero, ¿por qué excluir esta alternativa?, ¿en qué sentido la concepción kantiana del conocimiento a priori implica que el espacio no es una propiedad de las cosas en sí? La idea central de la primera etapa del tercer argumento es, según Guyer, que Kant concibe las proposiciones sintéticas $a$ priori como proposiciones que expresan una necesidad absoluta y no una necesidad condicional o relativa, y ello impide que podamos atribuir propiedades a priori al objeto en sí, ya que si lo fueran no serían conocidas como necesarias. Esta idea - dice Guyer- está en el centro de la revolución copernicana de Kant: si la representación depende del objeto, entonces no parece posible conocer algo a priori sobre los objetos, porque independientemente de nuestra experiencia no es posible saber si un objeto tiene, de hecho, cierta propiedad. ${ }^{40}$ Como Kant decía desde su segundo prólogo (B XVIII): lo que sabemos a priori de las cosas es sólo lo que nosotros mismos ponemos en ellas. En particular, si atribuimos al objeto mismo las propiedades espaciales, nuestro conocimiento de dichas propiedades dependerá del conocimiento del objeto y, por consiguiente, dicho conocimiento será empírico y contingente, y no a priori como se ha mostrado ser. Porque, ien qué sentido algo es una propiedad necesaria? Lo es en tanto el objeto no puede carecer de ella, ¿pero en qué sentido no puede carecer de ella?, ies porque sin ella no sería un objeto?, ¿o es porque sin ella no sería representable? Podríamos inclinarnos por la segunda respuesta y pensar que las propiedades a priori son necesarias porque son rasgos obligados de toda representación. Esto es lo que Guyer entiende por una necesidad relativa o condicional del a priori. ${ }^{41}$ De acuerdo con este concepto de necesidad, un juicio sintético a priori podría reformularse mediante una necesidad de dicto, de manera que, si " $x$ es espacial" es un juicio de este tipo, ello significa que:

Es necesario que si $x$ es un objeto percibido, $x$ sea espacial.

Si Kant optara por esta interpretación de la necesidad sintética no tendría por qué comprometerse con el idealismo; de hecho, en este caso - como sugiere Guyer - el realismo podría constituir la "mejor explicación" de esta necesidad: es necesario que lo que percibamos sea espacio-temporal, dado que las cosas que percibimos son, ellas mismas, espacio-temporales. Sin embargo, de acuerdo con Guyer, Kant no da esta interpretación al conocimiento a priori, sino una interpretación absoluta, de modo que, según este

40 Cfr. ibid., p. 362.

41 Más adelante recojo la intuición de Guyer sin citarlo textualmente pero siendo fiel a sus formulaciones de la p. 364. 
concepto de necesidad, el mismo juicio sintético a priori debería reformularse usando una modalidad de re:

Si $x$ es un objeto percibido, entonces $x$ es necesariamente espacial.

Kant piensa que lo que tiene - necesariamente- la propiedad es el objeto percibido y no meramente la representación del objeto percibido. La necesidad no es, pues, relativa a las condiciones cognoscitivas sino absoluta, constitutiva del objeto, sólo que al no poder ser constitutiva del objeto en sí, deberá ser constitutiva del objeto de representación. La idea central es que, para Kant, las propiedades a priori (conocidas como necesarias) no pueden ser propiedades de las cosas en sí porque, de serlo, nuestro conocimiento de las mismas dependería de nuestra percepción del objeto y, por consiguiente, sólo podríamos conocerlas a posteriori, es decir, como propiedades contingentes - y no necesarias - del mismo; y parece claro que algo no puede ser atribuido a la misma cosa, a la vez, como propiedad necesaria y como propiedad contingente.

Guyer objeta que aquí Kant da un paso en falso, ya que podría suceder que una propiedad fuera contingente respecto al objeto pero necesaria respecto a nuestro conocimiento del objeto, es decir, que pudiéramos predicar de ella una necesidad de dicto (condicionada a nuestra percepción del objeto) pero no una necesidad de re. En particular, podríamos decir que es necesario que todo objeto percibido sea espacial, sin por ello admitir que el objeto debe ser esencialmente espacial. Keaparece la alternativa desatendida por Kant: podría ser que el espacio fuera una propiedad de la representación del objeto ( $\mathrm{y}$ en este sentido una propiedad a priori, necesaria) y, a la vez, una propiedad del objeto en sí. Guyer se pregunta:

¿por qué [Kant] supone que la espacialidad genuina de las cosas en sí mismas es incompatible con nuestro conocimiento a priori de la espacialidad, en vez de constituir la mejor explicación de ello?

Siempre podríamos decir - al revés que Kant - que la espacialidad es una condición necesaria de la percepción de los objetos, justamente porque es una propiedad genuina de los mismos. ${ }^{42}$ No es que el realismo sea, de hecho, incompatible con el conocimiento a priori, lo que sucede es que es incompatible con la concepción kantiana del conocimiento a priori. Y en este punto es donde entra la importancia de la geometría como un corpus de proposiciones sintéticas a priori; son este tipo de verdades las que parecen requerir una interpretación absoluta de la necesidad. Es decir, si Kant se conformara con los resultados de la exposición metafísica no podría concluir este segundo tipo de necesidad y, por consiguiente, tampoco el idealismo; para ello tiene que apelar al tipo de juicios que formula la 
geometría -euclídea- como ciencia apodíctica. Porque parece claro que, respecto a los juicios específicos de la geometría, una interpretación condicional de la necesidad no es la adecuada, aquí lo que es necesario no es que si nos representamos, por ejemplo, un triángulo, éste tenga determinada propiedad, sino que el triángulo mismo posea dicha propiedad a priori, como una propiedad esencial y no meramente contingente. ${ }^{43} \mathrm{El}$ pasaje que mejor apoya esta interpretación de Guyer está al final de la Estética, donde Kant se pregunta por las condiciones en las cuales las proposiciones geométricas son verdaderas y concluye:

si el objeto (el triángulo) fuera algo en sí mismo, sin relación con nosotros como sujetos, ¿cómo podríamos decir que lo que se halla necesariamente en nosotros como condición subjetiva para formar un triángulo pertenece también, de modo necesario, al triángulo en sí mismo? (B 65)

Si entiendo bien la interpretación de Guyer, el punto es que si pensamos en objetos empíricos espaciales, como sillas, mesas, etc., podríamos interpretar el carácter a priori del espacio como condicional: lo que es necesario es que siempre que percibamos o nos representemos un objeto de este tipo, éste sea espacial. Pero con los objetos geométricos la espacialidad parece tener un carácter distinto, las propiedades espaciales específicas de un triángulo no son sólo criterios para nuestro conocimiento de los triángulos, sino asimismo parte esencial de lo que es un triángulo y de lo que su concepto significa.

De acuerdo con la interpretación anterior de Allison, el idealismo podía concluirse sin apelar a hipotesis adicionales, por consiguiente, es inmune a la existencia de otras geometrías; rechazar la necesidad de la geometría euclídea no implica abandonar el idealismo. Para Allison, el interés kantiano por dar cuenta de la geometría euclídea como ciencia apodíctica fue un motivo más bien que una razón para optar por el idealismo, es algo adicional con lo cual el hombre del siglo XVIII estaba comprometido, pero no así su filosofía. Por su parte, Guyer acepta que en principio la exposición metafísica del espacio (la tesis de que el espacio es una intuición pura), previa al idealismo, no está comprometida con la verdad de ninguna geometría particular y podría ser consistente con una geometría no euclídea; sin embargo, para Kant la creencia de que la geometría euclídea es necesariamente verdadera es algo más que un motivo de su opción por el idealismo: es un fundamento indispensable para aceptarlo. A diferencia de Allison, Guyer considera la exposición metafísica previa insuficiente para concluir la idealidad del espacio. En este sentido, rechazar el carácter apodíctico de la geometría euclídea echa abajo el idealismo kantiano, ya que desaparece la razón para considerar la necesidad a priori absoluta en vez de relativa. 
El argumento de los Prolegómenos, lejos de ser una mera vulgarización o síntesis de un argumento más complejo, es el único argumento capaz de producir por conclusión el idealismo. ${ }^{44}$ Como al final de la sección anterior, se nos propone quedarnos con una parte del argumento kantiano, a saber: que la espacialidad es una condición necesaria de nuestra representación de objetos, sin pronunciarnos por la razón que hace que esto sea así, o como sugiere el propio Guyer, podemos quedarnos con una necesidad condicional y un realismo como "su mejor explicación", en vez de con una necesidad absoluta y un idealismo problemático.

Creo que la interpretación de Guyer es muy atractiva. No obstante, hay dos puntos que quisiera objetar. En primer lugar, no me parece acertada la afirmación de que la distinción entre fenómeno y cosa en sí es un supuesto y no una consecuencia del idealismo. De hecho, la distinción cambia radicalmente según sea previa o posterior a la tesis idealista. De acuerdo con la lectura de Guyer, podríamos decir que su distinción primordialmente recoge la diferencia básica que hay entre una representación y su objeto. En este contexto, la cosa en sí es el objeto que percibimos por medio de la sensación y al cual podríamos atribuir la espacialidad, aunque sólo como una propiedad contingente. Este sentido supone que el concepto de cosa en sí es básicamente plural -es decir, hay tantas cosas en sí como objetos de percepción- y básicamente positivo: es aquello que nos afecta y que podemos conocer aunque sólo a posteriori. El término aún no se cubre de aquel carácter de incognoscible que le brinda el idealismo. Pero por esto mismo, la "cosa en sí" a la que aquí se alude no es el algo independiente de la representación, sino más bien el algo que nos es dado por medio de la sensación (lo que Kant en algunas ocasiones llama "materia de experiencia"). La distinción previa al idealismo, a la que alude Guyer, es, me parece, más bien la distinción entre representación y causa o materia de la representación que la distinción entre fenómeno y cosa en sí. De hecho, en los pasajes de las Reflexiones de Kant que cita Guyer siempre podríamos leer "causa de la percepción" u "objeto de la percepción" (en vez de "objeto en si") y el sentido sería el mismo; ello no sucede en cambio con el pasaje de la Estética que cita el propio Guyer (supra, p. 161), el cual no está casualmente después del argumento del idealismo.

Para reforzar este punto, cabe recordar el sentido austero de esta distinción entre fenómeno y cosa en sí, que aunque no es el único que Kant ofrece, sí es el que resulta más armónico con el agnosticismo que él siempre debió haber mantenido respecto a la realidad independiente del conocimiento: los fenómenos son los objetos de conocimiento y podemos saber a priori ciertas cosas acerca de ellos, por ejemplo, que han de ser espaciales si hemos de considerarlos una pluralidad de objetos externos. En cambio, de la cosa en 
sí no podemos hablar más que en singular, su plural no tiene sentido puesto que, según el primer argumento de la Exposición metafísica, nuestro único criterio para diferenciar objetos -y por consiguiente para usar el plural de un nombre- es el espacio. La cosa en sí significa tan sólo el algo independiente del conocimiento. Pensamos la cosa en sí, o la realidad en sí, como referente último, pero sólo cuando queremos respaldar nuestra intuición de que el conocimiento no es un juego de representaciones que da vueltas sobre sí mismo, refiriendo siempre representaciones a representaciones (a manera de un diccionario que refiere unas palabras a otras sin nunca "ir a las cosas mismas"); entonces ponemos la mirada en aquello a lo que, en última instancia, se refieren nuestras sensaciones. Finalmente, la cosa en sí es sólo un recordatorio de que, aun cuando nos movemos en un mundo de fenómenos, somos afectados por fenómenos y hablamos de fenómenos, no debemos olvidar que los fenómenos no son creación completa de la mente. Estrictamente, es sólo como un recordatorio de los límites del idealismo que podemos hablar de una positividad de la cosa en sí. La distinción puede y debe ser vista, me parece, como la introducción de un concepto austero y negativo de una cosa en sí, que en vez de producir fantasmas, los elimina. Es decir, al identificar el fenómeno con el objeto espacio-temporal, Kant está señalando que nuestra realidad (donde nacemos, nos movemos y de la cual hablamos) es una realidad fenoménica y que la realidad independiente de todo conocimiento es algo de lo que podemos olvidarnos de una vez por todas en el nivel cotidiano.

Hay un detalle muy revelador en el discurso de la cosa en sí que ayuda a precisar más estas dos interpretaciones del término. Cuando el discurso es en plural y se habla de "cosas en si", automáticamente pensamos en una realidad paralela a nuestra realidad, esto introduce dos fantasmas que Guyer (quien no casualmente siempre habla en plural) señala acertadamente: por un lado, la presencia de una realidad de entrada inaccesible; por otro, la sugerencia de que nuestro conocimiento no es sino un juego de representaciones. Para Guyer, el idealismo kantiano degrada los objetos a meras representaciones, finalmente, a entidades mentales. ${ }^{45}$ El uso singular del término, en cambio, modifica radicalmente la perspectiva: la cosa en sí, o realidad en sí, es un referente último, un algo indeterminado, una explicación - más bien que una causa- última de nuestras percepciones. ${ }^{46}$

Mi segunda objección está relacionada con lo anterior. No me parece casual que Guyer retome para su reconstrucción sólo tres de los cuatro argumentos que forman parte del parágrafo final de la Estética. En el punto

45 Cfr. Guyer, op. cit., p. 335.

46 En el contexto de otra discusión (el realismo científico) Putnam sugiere esta interpretación "austera" y Pérez Ransanz la desarrolla señalando sus ventajas. Al respecto, cfr. Pérez Ransanz, "La perspectiva internalista Putnam", en Khun y el cambio científico, especialmente la sección 11.3 (en prensa). 
ignorado (B 69-71), Kant subraya una ventaja adicional de su tesis idealista: ella hace desaparecer el abismo que suele haber entre apariencia y realidad, ya que concibe los objetos de conocimiento como algo que podemos conocer y no como algo sobre lo que elaboramos sólo conjeturas; el que los objetos sean fenómenos no los convierte en meras apariencias, al contrario, elimina fantasmas. Aceptar la existencia de cosas en sí finalmente vuelve irrealizable el propósito de cualquier conocimiento: la coincidencia con su objeto. El argumento de Kant sugiere que pensar los objetos de conocimiento como cosas en sí vuelve la pregunta escéptica lacerante: ¿cómo saber que todo aquello que vale para nuestra representación vale también para las cosas en sí? Guyer sugiere: "porque pensar que es así constituye nuestra mejor explicación", pero para Kant esto no basta. Para dar una respuesta definitiva al escéptico la mejor explicación no es el realismo, sino la aceptación de que los objetos de conocimiento son constituidos parcialmente por el sujeto.

Pero si esto es así, si el objeto al que se refiere el conocimiento no es una cosa en sí, sino un objeto parcialmente construido por nuestra intuición y conceptualización, entonces no veo por qué no podríamos predicar de él la espacialidad a manera de una propiedad necesaria, ya que es justamente esto (su espacialidad) lo que constituye uno de los rasgos "esenciales" de cualquier objeto externo que podamos conocer. $\mathrm{Si}$, a diferencia de Guyer, aceptamos una tercera categoría básica (el objeto de conocimiento como algo diferente de la representación pero también diferente de la cosa en sí), entonces el argumento de Kant podría recuperar una necesidad en el objeto, aunque relativa a nuestro conocimiento del mismo. De esta manera, un argumento que pretende ser trascendental y que está respaldado en el idealismo (i.e., la tesis de que el objeto es constituido parcialmente por el conocimiento) no tendría por qué transformarse en un argumento en favor del realismo como "la mejor explicación" de la espacialidad de los objetos.

Guyer tiene razón, me parece, en que no podemos pretender una "necesidad absoluta", pero no la tiene al pensar que Kant buscó este tipo de necesidad. Para Kant, la necesidad absoluta es también "el verdadero abismo de la razón humana", lo que pretende es una necesidad relativa pero, eso sí, en las cosas. La distinción entre necesidad de dicto y necesidad de re no corresponde a la distinción entre necesidad condicional y absoluta, como piensa Guyer. De hecho, podemos combinar ambas y hablar de cuatro tipos de necesidades posibles: a) una necesidad de dicto absoluta, que sería la que poseen las tautologías, una necesidad puramente formal, carente de todo contenido; b) una necesidad de dicto pero relativa, que es la que parecerían pretender los enunciados analíticos pero no tautológicos; c) una necesidad absoluta de re que es prohibitiva, y, finalmente, d) una necesidad de re pero relativa a las condiciones epistémicas, expresada en proposiciones sintéticas a priori y que es la que atrae el mayor interés de Kant. 
En resumen. La identificación que mantiene Guyer entre la cosa en sí y el objeto que causa nuestras sensaciones ( $\mathrm{y}$ que, sin duda, encuentra apoyo en varios párrafos de la Crítica) permea toda su interpretación. De hecho, su crítica central acerca de que Kant comete una falacia al concluir una necesidad en los objetos (de re) a partir de una necesidad conceptual (de dicto) se apoya en la idea de que la inferencia es imposible porque el objeto es algo esencialmente independiente de la representación. En la medida en que el objeto se acerque o se identifique (al menos parcialmente) con la representación, el tránsito de una necesidad a otra se hace posible. Es decir, si aceptáramos el idealismo entendido como la tesis de que el objeto de conocimiento parcialmente es determinado o constituido por las condiciones de conocimiento, entonces quizá podremos pasar de una necesidad a otra, aunque quizá sólo en el caso de aquellos rasgos que resulten obligados en virtud de ciertas condiciones a priori de conocimiento. De cualquier manera, precisar con más detalle esta posibilidad implicaría alejarnos demasiado de nuestro tema; por ello, dejo esto a manera de sugerencia y abandono la interpretación de Guyer para analizar la tercera y última interpretación acerca de las razones de Kant para aceptar el idealismo.

\section{La propuesta de Kitcher}

Patricia Kitcher acepta que la tesis idealista es compatible con el status del espacio como intuición a priori y también acepta que dicha tesis hace posible, para Kant, explicar que nuestro conocimiento geométrico sea sintético a priori. Pero estas dos razones no son, nos dice, las únicas que hacen optar a Kant por el idealismo; de tal manera que si ellas no son suficientes para concluir el idealismo, aún cabe apelar a una tercera razón: el idealismo le permite a Kant resolver una de las polémicas más importantes de su época: la discusión sobre la percepción de propiedades espaciales. Es en este tercer punto donde ahonda la interpretación de Kitcher. ${ }^{47}$

De acuerdo con esta lectura, en la época de Kant aún está vigente la discusión sobre la percepción de figuras y distancias que, según Cassirer, es un campo tradicional de batalla entre empiristas y racionalistas. ${ }^{48} \mathrm{El}$ problema se remite a Molyneaux, de quien toma el nombre y quien lo plantea a manera de una adivinanza: supongamos un ciego de nacimiento que reconoce y distingue por el tacto una figura cúbica de una redonda; si este ciego recuperara la vista: ¿podría reconocer las figuras por la vista, sin tocarlas? y, ¿podría saber a qué distancia están dichas figuras, sin alargar

47 En los siguientes párrafos resumo la exposición de Patricia Kitcher, Kant's Transcendental Psychology, Oxford University Press, Oxford, 1990, cap. 2.

48 Para un análisis más detallado de la historia de este problema consúltese la introducción de Carmen Silva, así como los diversos textos de la antología El problema de Molyneaux, L. Benítez, J.A. Robles y C. Silva (comps.) (en prensa). 
la mano para alcanzarlas? Como bien señala Carmen Silva, es la primera pregunta -el reconocimiento de figuras- - la que en un principio despierta toda la atención, especialmente de Locke, sin embargo, la justificación más sólida a la respuesta negativa fue dada por Berkeley quien, como veremos, enfrenta el problema más bien por la segunda pregunta -la percepción de las distancias. ${ }^{49} \mathrm{Y}$ es más bien esta segunda vertiente de la polémica la que más le interesa a Kitcher, el problema de si podemos inferir conocimiento de distancias - y por consiguiente, la tridimensionalidad - a partir de las imágenes que nos ofrece la visión. En un principio, señala Kitcher, hay básicamente dos opciones: la postura racionalista, defendida por Descartes y sus seguidores, según la cual inferimos distancias (y por ende, la tridimensionalidad de los objetos) a partir de las imágenes visuales, ya que poseemos una "geometría natural", innata. Por otro lado, la propuesta empirista de Berkeley, según la cual el conocimiento de las distancias lo obtenemos gracias al tacto y la tridimensionalidad la inferimos a partir de los datos sensibles, sin acudir a nada innato. La alternativa empirista ganó muchos adeptos -nos dice Kitcher - tras la operación de un adolescente ciego, el cual era incapaz de dirimir distancias a partir de sus primeras imágenes y sentía que lo que veía se le venía encima y "tocaba" sus ojos. ${ }^{50}$ Pero tiempo después, el argumento de Berkeley fue puesto en duda por Leibniz, quien, en sus Nuevos ensayos, argumenta con base en nuevos experimentos que un paralítico total, incapaz de tocar cosas, es tan capaz de aprender geometría como un ciego y que, por ende, nuestras ideas del espacio son independientes de las imágenes que nos ofrece la vista, pero también de aquellas que nos ofrece el tacto. ${ }^{51}$

De acuerdo con Kitcher, la distinción kantiana entre sensación e intuición sugiere una postura alternativa a las esbozadas hasta aquí y más cercana a Leibniz que a Descartes o a Berkeley. ${ }^{52}$ A Kant —como a Descartes-le tienta la idea de una geometría a priori, pero también le convence Berkeley (a pesar de que, como a Newton, nunca lo menciona explícitamente) y acepta que es el tacto lo que nos da la idea de volumen. ${ }^{53}$ Pero es una tercera

49 Cfr. ibid. sección 4 de la introducción de Silva.

50 Cfr. Kitcher, op. cit., p. 33.

51 Cfr. ibid., p. 42.

52 Siguiendo la exposición de la introducción de Silva (op. cit., sección 7), podría decirse que la respuesta de Kant - de acuerdo con Kitcher- es una mezcla de Leibniz y Synge, en tanto la distinción entre "sensación e intuición" podría desempeñar un papel similar al que desempeña, en su contexto, la distinción "imágenes e ideas" de Synge. También podría decirse -y sería quizá la contribución más acertada, sugiere.Carmen Silva-que Kant introduce una nueva manera de enfrentar el problema, en tanto habla de percepción del espacio y ya no de percepción visual; la percepción del espacio (externa) sería un resultado sistemático de los datos provenientes de los sentidos.

53 Cfr. Anthropologie, trad. Michel Foucault, Vrin, París, 1988, pp. 37-38, publicada mucho después de recopilada. De acuerdo con Kitcher, Kant también acepta explícitamente que un 
postura la que es más afín a Kant: hay una facultad a priori que permite coordinar los datos sensoriales y relacionarlos espacio-temporalmente. Al inicio de la Estética, Kant introduce la idea de que la intuición requiere además de una materia (las sensaciones), una forma que no puede, ella misma, ser sensación, ya que es la que relaciona las diferentes sensaciones para constituir un fenómeno, por consiguiente:

la forma pura de las intuiciones sensibles en general, donde se intuyen en ciertas relaciones toda la diversidad de los fenómenos, se hallará a priori en la mente. (B 34) ${ }^{54}$

De acuerdo con Patricia Kitcher, este pasaje es una clave para entender la opción de Kant por el idealismo; parafraseo brevemente su reconstrucción del argumento:

1. Dado que sensaciones e intuiciones no son lo mismo, debe haber un proceso que nos permita formar intuiciones a partir de sensaciones.

2. Hay una forma común en toda intuición, una relación determinada entre sus elementos.

3. Si hay cierta forma común en las intuiciones, entonces debe haber una forma común de procesar las sensaciones para dar a la intuición dicha forma.

4. Si hay tal forma común de procesar, ella deberá "hallarse a priori en la mente". 55

A partir de aquí, Kitcher hace notar que Kant pretende dar a las intuiciones puras un status a priori en el sentido especifico del origen, es decir, $a$ priori en tanto dichas formas no pueden derivarse de la sensación, sino que "debe tener otra fuente". Sin embargo, Kant se cuidó de no identificar este sentido de a priori con el innatismo. Apelar al innatismo es pretender dar una explicación causal de por qué dichas formas tienen un origen a priori, $\mathrm{y}$-como señala Kitcher - Kant evita dar explicaciones causales adicionales, quizá de manera similar a como Newton evitaba (hipotesis non fingo) postular una causa de la gravitación universal. Kant admite en su "Carta a Ebrahard", que el fundamento de este proceso podría ser algo innato, pero que ello no implica que la representación del espacio misma sea innata, es decir, ni la forma de representar ni la forma de lo representado son innatas, sólo lo es, en todo caso, el fundamento último de las mismas, y ello a

ciego que recupera la vista mediante una operación debe aprender a ver, pero quizá dicha afirmación no está incluida en la edición mencionada.

54 Ribas usa 'psiquismo', García Morente 'espíritu', yo prefiero la traducción que sugiere Pedro Stepanenko de 'mente'.

55 Cfr. Kitcher, op. cit., pp. 36-37. 
manera de una hipótesis causal adicional y prescindible. ${ }^{56}$ Las formas son vacías, sin materia dichas formas no son formas de nada. Pero el hecho de que determinada forma esté presente en toda representación, le da una independencia respecto a nuestras sensaciones concretas. El argumento se centra en el hecho de que hay una forma común de toda intuición, es decir, en el punto 2. Pero, ¿cuál es esta forma?

Para identificar dicha forma, Kitcher acude al método de separación; la forma común de toda intuición se descubre si hacemos abstracción de todos los elementos sensibles de dicha intuición (que se refieran a sensaciones), de esta manera abstraemos el color, la textura, la dureza, etc., y nos quedamos con figura y extensión. Para Kitcher, el experimento Gedanken de Kant está íntimamente relacionado con la discusión precedente sobre la percepción de distancias: si ni la visión ni el tacto dan cuenta de figuras, tamaños y distancias, y no obstante percibimos objetos en coordenadas espaciales, entonces: "se sigue que las propiedades espaciales de los objetos son puras, formas a priori [respecto a su origen] de la intuición, y cualquier teoría posible de la percepción del espacio debe apelar a algún proceso formal puro o a priori [respecto a su origen]". ${ }^{57}$ De hecho, lo que Kant pretende es señalar que nuestros sentidos externos emplean un modo común de representación espacial (cfr. B-37), un modo que es independiente de los materiales dados a través suyo.

Kitcher plantea una tercera interpretación, alternativa a las anteriores. Con el objeto de comparar su lectura con las otras dos, retomo su distinción entre tipos de a priori. De acuerdo con Kitcher, ${ }^{58}$ en Kant hay tres acepciones del término, la primera de ellas se refiere a un a priori respecto a las proposiciones necesarias y universales: a priori $i_{L}$. El segundo sentido es cuando el término se refiere al origen de una representación, en tanto ésta "no deriva de la sensación": puro o a priorio. Finalmente, la tercera acepción es epistémica y se refiere al conocimiento (que se justifica) "independiente de toda experiencia": a priori ${ }_{K}$. Ahora bien, si aceptamos que es el $a$ priorio el que resulta fundamental para afirmar la subjetividad de las formas, y por consiguiente el idealismo, 59 ya que implica un elemento presente en toda intuición que no se debe a la sensación, es decir, no puede remitirse a lo que nos es dado (y por consiguiente, tendría que deberse a lo "que nosotros ponemos"), entonces podríamos decir que:

56 Cfr. "¿Por qué no es inútil una nueva crítica de la razón pura? Respuesta a Ebrahard", y Kitcher, op. cit., pp. 38-39.

57 Kitcher, op. cit., p. 43.

58 Ibid., introducción, pp. 15-16.

59 Tal como afirma Kant en la última cita que recogimos (supra, p. 165), y como lo desglosa Kitcher en los puntos 3 y 4 de su reconstrucción del argumento (supra, p. 170). 
La reconstrucción de Allison toma como algo fundamental la tesis de que la representación del espacio es a priori ${ }_{K}$ (como se ha demostrado en los argumentos de la exposición metafísica) y argumenta que, por ende, la representación del espacio debe ser a priorio (es decir, del espacio como intuición pura al espacio como forma de la sensibilidad), lo cual, a su vez, implica como consecuencia la posibilidad de la geometría como un corpus de proposiciones a priori $_{L}$. De esta forma, para Allison, el a priori $i_{K}$ conduce al $a$ priorio y el a priorio explica el a priori $i_{L}$. A diferencia de Allison, Kitcher piensa que el $a$ priorio es el primero que se introduce, de hecho, está ya presente en la exposición metafísica. Así, por ejemplo, en el primer argumento, dice Kitcher, Kant pretende mostrar que el espacio no es un concepto empírico; sin embargo, como bien se ha señalado (entre otros por Maas), el ser indispensable para la representación de objetos no convierte el espacio en algo separable de los objetos, no implica que el espacio - a diferencia de todo otro contenido empírico- no pueda ser adquirido a partir de nuestras sensaciones. Para librarse de esto, el Kant de Kitcher requiere la tesis adicional de que las propiedades espaciales no pueden provenir de la sensación, es decir, requiere que el espacio sea a priorio, y afirma el carácter a priorio de nuestra representación del espacio porque sabe que dicho carácter no depende de la información del tacto o de la vista. ${ }^{60}$ A su vez, el segundo argumento de la exposición metafísica supone también este elemento puro: con este argumento, Kant estaría, por así decirlo, forzando a Leibniz a ser coherente: si dentro de la polémica sobre la percepción de la tridimensionalidad, Leibniz acepta que la idea del espacio es independiente de las imágenes de los sentidos (es decir, es a priorio), no puede entonces considerar - como lo hace en su carta a Clarke- que el espacio es algo confusamente abstraído de las representaciones. ${ }^{61}$ De aquí que para Kitcher: el a priorio implique el $a$ priori $i_{K}$.

La reconstrucción de Guyer, en cambio, toma como premisa fundamental la existencia de proposiciones a priori $i_{L}$, y argumenta que es sólo a partir de ellas que Kant obtiene el status a priorio de la representación del espacio. Y ello, después de negar que el conocimiento a priori $i_{K}$ que poseemos acerca del espacio sea suficiente para derivar su carácter de a priorio (lo que es válido para la representación puede no serlo para el objeto). De esta forma, para Guyer, el $a$ priori $i_{L}$ justifica el a priorio, pero el a priori $i_{K}$ no conduce al a priorio. A diferencia de Guyer, Kitcher piensa que el orden de la Estética muestra que la pretensión original kantiana no es partir de la necesidad —a priori $_{L}$ - de la geometría euclídea, sino más bien explicarla a manera de una ventaja de la espacialidad como un carácter originalmente puro (a priorio). La geometría debe verse "como una confirmación más bien que como una

60 Cfr. ibid., p. 47.

61 Cfr. ibid., pp. 48-49. 
raison d'être". ${ }^{62}$ Kitcher se detiene a analizar de qué manera se obtiene el a priori $i_{L}$ respecto a la geometría euclídea. Para ello, Kant deberá defender que el elemento puro ( $a$ priorio) de la intuición - la forma independiente de toda sensación - no sólo es la espacialidad, sino la espacialidad específicamente euclídea. Y, a sli vez, lo que permite afirmar esto último es que podemos tener conocimiento del espacio independientemente de toda experiencia (a priori $i_{K}$ ), por medio de lo cual sabemos que éste es euclídeo. Kitcher dedica la última parte de su capítulo a evaluar esta tesis de que el espacio de la percepción es euclídeo con el objeto, quizá, de explorar otra forma de defender la validez de la geometría euclídea: si no define el espacio físico, sí podría quizá definir el espacio de la percepción humana. Pero dejemos aquí su exposición.

La postura es original e interesante, y el hecho de que Kant no aluda a la polémica directamente no es decisivo para desechar su interpretación, al respecto Kitcher aduce que probablemente Kant no aludió a ello (como tampoco aludió específicamente a Newton en la Estética) porque era algo que todo el mundo sabía y flotaba en el ambiente. Sin embargo, independientemente de que el silencio de Kant no deja de ser algo extraño, veo dos dificultades en su lectura: la primera es que deja aislado el tiempo, mucho más de lo que ya de por sí Kant lo aisló en esta sección; los argumentos de Kitcher dan plausibilidad a la idea de que Kant haya concedido al espacio un status privilegiado, pero no así al tiempo, que queda flotando desamparado en espera de un argumento similar. La segunda, y más importante, es el hecho de que el afán de Kant por dar cuenta de nuestro conocimiento de distancias y tamaños podía haberlo llevado a aceptar el status de intuición $a$ priori del espacio, sin concluir por ello su subjetividad. La única razón adicional que de acuerdo con Kitcher tiene Kant para afirmar que el espacio es una forma $a$ priorio de nuestras intuiciones es, me parece, el experimento Gedanken que nos invita a aislar la intuición de todos sus componentes sensibles hasta dar con aquello que "no tiene su origen en la sensación". Y aunque es cierto que en el contexto de la polémica sobre la percepción este experimento adquiere un sentido peculiar, ello no es suficiente para lograr lo que pretende: ya que, por un lado, icómo sabemos - como pregunta Strawson- que con independencia de todo objeto, "extensión y figura" no son sólo palabras sin sentido?, pues, ¿qué es una figura independientemente de todo contorno que podamos dibujar o tocar?; por otro lado, podríamos aceptar que la figura y la extensión sean independientes de cada uno de nuestros sentidos sin aceptar, por ello, que son independientes de todos a la vez. A mi forma de ver, Kitcher ha descubierto una ventaja

62 Ibid., p. 50. Contra Guyer, Kitcher aduce el dato de que, de acuerdo con Ted Humphrey, Kant no desarrolló la distinción analítico-sintético, esencial para el status de las proposiciones de la geometría, sino hasta después de la Disertación inaugural y la Crítica respeta básicamente la doctrina del espacio ahí presentada. 
adicional de la teoría kantiana sobre el espacio, a saber: que resuelve una disputa tradicional; pero no necesariamente ha encontrado una razón para apoyar la inferencia decisiva: un experimento dudoso no puede ser el pilar principal del idealismo.

\section{Conclusiones}

A partir de lo dicho atrás podemos concluir que el idealismo no es una conclusión obligada de la Estética trascendental. No basta la exposición metafísica para respaldarlo, tampoco basta la creencia - falsa - de que la geometría euclídea es un corpus de proposiciones necesarias; tampoco basta pensar que de esta forma se da cuenta de problemas de percepción que, además, se apuntalan en experimentos dudosos.

Me gustaría, sin embargo, rescatar lo que considero las virtudes principales de las interpretaciones que he expuesto críticamente atrás, pero ahora de manera mezclada y formar mis propias conclusiones. El primer punto importante es reconocer que el espacio funciona como un criterio fundamental de ubicación y diferenciación de particulares. Para que desempeñe correctamente esta función se requiere, además, considerarlo único y potencialmente infinito. El espacio como "intuición a priori" expresa la idea de un armazón, una estructura, unas coordenadas básicas, que nos permiten ubicar y reubicar sensaciones, representaciones y luego objetos. Sólo que no es un orden particular, "confusamente abstraído" de la experiencia, sino una condición, un abanico o ámbito de órdenes posibles entre sensaciones, representaciones y objetos. El espacio es un ámbito de posibilidades donde construir objetos vía definiciones y donde ubicar objetos vía percepciones.

Ahora bien, este papel fundamental no implica que el espacio sea sólo dicha estructura de orden y nada más. Bien podría ser una propiedad de los objetos o una cosa real. El siguiente paso de Kant tendría que haber sido el decidirse frontalmente por el agnosticismo: la posibilidad de que el espacio sea algo más que esta estructura básica está abierta, sólo que a nosotros nos interesa únicamente lo que se ajusta a ella; justamente su función es delimitar un ámbito de conocimiento posible. Nos interesan las cosas que se ajustan a esta condición (provenga de donde provenga) y no las cosas independientemente de si se ajustan o no a esta condición. La solución parece ser rechazar la tesis idealista de Kant en tanto ella se opone al sano agnosticismo. Si el idealismo trascedental consiste - como Kant sugiere, no sólo en la Estética- ${ }^{63}$ en afirmar que las cosas en sí no son espacio-temporales, entonces está equivocado: no sabemos cómo sean las cosas en sí, ni siquiera sabemos si hay cosas en sí. 
Pero hay otra forma de retomar el idealimso y es considerarlo como la tesis general de que la representación modifica su objeto. Interpretado así, el idealismo nos permite afirmar no sólo que las representaciones de objetos son necesariamente espaciales, sino que los objetos que conocemos por medio de ellas también lo son. El idealismo como mera afirmación de un condicionamiento en el objeto -dadas las condiciones epistémicasnos permite un conocimiento de rasgos necesarios de los objetos. Pero no porque el idealismo nos permita llegar a las cosas en sí y decir cómo son, sino porque nos permite justamente lo contrario, olvidarnos de las cosas en sí y poner la atención en el fenómeno como aquello que es objeto de nuestra representación. En este sentido, el espacio ayuda, por su función epistémica, a delinear un criterio ontológico básico: los objetos que podemos saber que existen son sólo aquellos que se ubican en este armazón fundamental.

Finalmente, es importante situar la tesis de Kant sobre el espacio entre Leibniz y Newton y para ello cabe retomar de Chenet dos ejes de preguntas: ${ }^{64}$ por un lado, está la posibilidad de que el espacio sea algo real o algo ideal, es decir, algo objetivo o algo subjetivo. Sobre este eje se sitúa la objeción de la alternativa desatendida de la que hemos estado hablando a lo largo de estas páginas: Kant opta, a diferencia de Newton (quien concibe el espacio como una entidad real) y Leibniz (quien lo concibe como relaciones entre cosas reales), por considerar el espacio algo ideal y ésta es la conclusión idealista que, pese a los esfuerzos de Kant, resulta forzada.

El otro eje de preguntas es sobre si el espacio es sustancia, propie Jad o relación. Newton concibe el espacio como una sustancia, Leibniz lo co cibe como una relación, Kant en cambio, ofrece una concepción más compl ja. El espacio kantiano parece ser, por una parte, una entidad no real sino fo mal, que sirve como "contenedor" de objetos (ya sea construidos o percibidos); como tal, el espacio posee propiedades y puede analizarse geométricamente. Respecto al espacio geométrico, Kant está cerca de Newton; el espacio es una estructura aunque no real, sí formal. Por otra parte el espacio kantiano parece ser fundamentalmente un criterio de ubicación y diferenciación de objetos, y la ubicación puede hacerse apelando a relaciones (aunque en el caso dé las réplicas incongruentes estas relaciones se definan no internamente, sino en relación con un sistema más amplio de particulares). El espacio es, para efectos de la percepción, un sistema de relaciones que nos permite la identificación. En este sentido Kant está, más bien, cerca de Leibniz: el espacio es un sistema de relaciones pero no determinado y confusamente abstraído sino anticipado a priori a manera de un abanico de órdenes posibles. Esta especificidad de la teoría del espacio de Kant puede recogerse diciendo que, para Kant, la espacialidad es una propiedad necesaria de los objetos de conocimiento (fenómenos). Lo es de los objetos 
geométricos éstos porque sólo pueden construirse en dicha estructura y lo es de los objetos de percepción porque cualquier objeto externo debe ubicarse necesariamente en algún posible sistema de relaciones espaciales. El espacio es anticipado sólo como un ámbito de posibilidades y es la experiencia y, sólo ella, la que nos dirá qué orden específico presentan sus objetos. 